\title{
Grinding of the Alloy INCONEL 718 and Final Roughness of the Surface and Material Share
}

Martin Novak, Natasa Naprstkova

Faculty of Production Technology and Management, J. E. Purkyne University in Usti nad Labem. Pasteurova 3334/7, 400 01 Usti nad Labem. Czech Republic. E-mail: novak@fvtm.ujep.cz, naprstkova@fvtm.ujep.cz

Grinding is currently still an important method for surface finishing. At FPTM JEPU is realized the research, which deals with this issue. There are carried out experiments with grinding various materials under different conditions and then are evaluated the selected components of the surface integrity, which are generally roughness $\mathrm{Ra}, \mathrm{Rz}$ and Rz, material ratio curve (Abbott Firestone curve) and also obtained roundness. This article deals with grinding nickel alloy Inconel 718, when selected cutting grinding conditions were used and subsequently the surface roughnesses $R a, R z$ and $R t$, the surface profile and the material ratio curve were measured and evaluated.

Keywords: Grinding, Roughness, Surface Quality, Abbott Firestone curve, Inconel

\section{Acknowledgement}

Above mentioned results were created by specific research in J. E. Purkyně University in Usti nad Labem.

\section{References}

[1] INCONEL ${ }^{\circledR}$ alloy 718 (UNS N07718) [online]. (2007) [cit. 2014-3-13]. Available at www http://www.hpalloy.com/alloys/descriptions/INCONEL718.html.

[2] INCONEL® alloy 718, company informations, [online]. (2007) [cit. 2014-3-13]. Availavle et www: http://www.specialmetals.com/documents/Inconel\%20alloy\%20718.pdf

[3] BAUER, R. (2008) Obrábění těžkoobrobitelných materiálů [online]. [cit. 2014-3-13]. Available at www http://www.mmspektrum.com/clanek/obrabeni-tezkoobrobitelnych-materialu.html.

[4] BRYCHTA, J., CEP, R., SADILEK, M., PETRIKOVSKÁ, L., NOVAKOVÁ, J. (2007) Nové směry v progresivním obrábění, p.251, Ostrava: VŠB,.

[5] BYRNE, P. (1996) Turning, milling and grinding processes. London, Arnold.

[6] CZAN, A., SAJGALIK, M., HOLUBJAK, J., KOURIL, K. (2013) Studying of Cutting Zone When Finishing Titanium Alloy by Application of Multifunction Measuring System. In: Manufacturing Technology, Vol. 13., No. 4, pp. 428-431, 2013.

[7] KOCMAN, K. (2012) Optimalizace dokončovacích operaci výrobních procesů. In: Strojírenská technologie, Vol. 17, No. 3, pp. 164-169, UJEP, Ústi nad Labem.

[8] JERSAK, J. (2012) Vliv dynamickeho vyvazeni brousiciho kotouce na drsnost povrchu obrobenych soucasti. In: Strojírenská technologie, Vol.17, No. 1,2, pp. 27-33, UJEP, Ústi nad Labem

[9] TAVODOVÁ, M. (2013) The surface quality of materials after cutting by abrasive water jet evaluated by selected methods. Manufacturing technology, Vol. 13, No. 2, p. 236-241, UJEP, Ústi nad Labem.

[10] NOVAK, M. (2011) Surface quality of hardened steels after grinding. In: Manufacturing Technology, Vol. 11, No. 11, pp. 55-59, UJEP, Ústi nad Labem.

[11] NOVAK, M. (2012) Surfaces with high precision of roughness after grinding. Manufacturing Technology, Vol. 12, No. 13, pp. 66-70, UJEP, Ústi nad Labem.

[12] OSIČKA K. (2009) Prumerna aritmeticka uchylka drsnosti povrchu - statisticke vyhodnoceni plochy. In: Strojirenska technologie. Vol. 14, No. 1. pp. 30-32, UJEP, Ústi nad Labem.

[13] NOVAK, N., KASUGA, H., OHMORI, H. (2013) Differences at the Surface Roughness by the ELID and Grinding Technology. In: Manufacturing Technology, Vol. 13, No. 2, p. 210-215, UJEP, Ústi nad Labem.

[14] VALICEK, J., RUSNAK, J., MULLER, M., HRABE, P., KADNAR, M., HLOCH, S., KUSNEROVA, M (2008) Geometricke aspekty drsnosti povrchu klasickych a netradicnich technologii. In: Jemná mechanika a optika, Vol. 53, No. 9, pp. 249-253.

[15] JUSKO, O. (2010) Vývoj a inovace brousicich nástroju. In: Strojírenská technologie. Vol. 15, No. 1, pp. 17-22, UJEP, Ústi nad Labem.

[16] NOVÁK, M. (2011) Studium jakosti brouseneho povrchu kalených ocelí, část I. - drsnost povrchu. Strojírenská technologie, Vol. 16, No. 6, pp. 26-33, UJEP, Ústi nad Labem,.

[17] KOUŘIL, K., CEP, R., JANASEK, A., KRIZ, A., STANCEKOVA, D. (2014) Surface integrity at reaming operation by MT3 head. In: Manufacturing Technology, Vol. 14, No. 2, pp.193-199, UJEP, Ústi nad Labem, 